\title{
Investigations on martensite formation in CrMnNi-TRIP steels
}

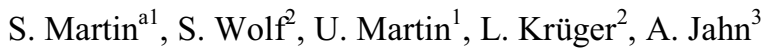 \\ ${ }^{1}$ Institute of Materials Science, Technische Universität Bergakademie Freiberg, 09596 Freiberg, Germany \\ ${ }^{2}$ Institute of Materials Engineering, Technische Universität Bergakademie Freiberg, 09596 Freiberg, Germany \\ ${ }^{3}$ Institute of Iron and Steel Technology, Technische Universität Bergakademie Freiberg, 09596 Freiberg, Ger- \\ many
}

\begin{abstract}
A new generation of high alloyed cast CrMnNi-TRIP-steels was developed exhibiting high strength (UTS) as well as high uniform elongation for a maximum of energy-absorption. The nature of the high elongation is the formation of $\alpha^{\prime}$-martensite in the most deformed areas of the metastable austenitic steel, so that necking is delayed. Because of the low stacking fault energy, due to the high alloying concept, deformation is mainly accompanied by the development of deformation bands in coarse austenitic grains and further the formation of $\alpha^{\prime}$-martensite. Within this study, stress-strain curves will be evaluated by the corresponding microstructure information obtained by LOM, SEM and EBSD examinations. The formation of $\alpha^{\prime}$-martensite is discussed for tensile and compressive loading at room temperature. The arrangement of martensite within the microstructure and the local deformation dependency of the $\alpha^{\prime}$-martensite fraction is considered. Martensite kinetics will be presented for interrupted deformation tests, determined via magnetic balance (MS), EBSD and light optical metallography (LOM).
\end{abstract}

\section{Introduction}

In order to achieve excellent properties regarding strength and ductility a high alloying concept using manganese for cast CrMnNi-TRIP-steels is developed [1]. Manganese has been used to decrease the stability of the austenite. Hence a metastable austenitic microstructure is achieved next to the triple point of austenite-ferritemartensite in the Schaeffler-diagram, which shows the microstructure components in dependence on the ferrite stabilising and austenite stabilising element concentration equivalents. This results in a phase transformation when the material is subjected to plastic deformation. The initial microstructure is quite different compared to low alloyed TRIP-steels. Austenite forms the main part of the microstructure with neither bainite nor martensite fractions. The possible deformation modes, which are dislocation slip, twinning and the phase transformation, constituting the TRIP-effect, are mainly influenced by the stacking fault energy (SFE) of the austenite [2]. The $\mathrm{SFE}$ is reduced by the addition of $6 \mathrm{wt} . \%$ manganese.

The deformation of stainless steel is accompanied by the formation of deformation bands within the austenitic grains. Deformation bands are formed by overlapping of successive stacking faults during plastic deformation [3]. Because of the low SFE, dislocations are able to diverge widely into two Shockley partial dislocations and therefore span an area where a stacking fault (SF) emerges. Depending on the periodicity of the stacking faults, different lattice configurations may be formed. Regularly distributed intrinsic stacking faults on every second $\{111\}$ slip plane of the metastable austenite cause an ABABAB stacking sequence and the formation of an hcp phase. A twin is created if the partial dislocations glide on successive $\{111\}$ fcc planes [3]. When stacking faults occur with irregular spacing, the region may be recognized as distorted fcc or hcp phase.

It is reported [4] that the SFE is a capable parameter to estimate which deformation mode can be expected. A SFE of $\gamma_{\mathrm{SF}}=20 \mathrm{~mJ} / \mathrm{m}^{2}$ seems to be a suitable threshold for steel to deform by formation of $\varepsilon$-martensite as hcp phase or above this critical value as well by twinning. Due to the fact that the SFE is a function of temperature [2,3], deformation modes change with deformation temperature. At high temperatures twinning is observed, followed by a transition mode, where twinning as well as the formation of $\varepsilon$-martensite is expected. Finally at low temperatures $\varepsilon$ - and $\alpha^{\prime}$-martensite formation is considered. Mainly the fraction of $\alpha^{\prime}$-martensite is responsible for the high workhardening capacity which is recognized e.g. at low temperatures [2, 5].

${ }^{a}$ e-mail: stefan.martineiww.tu-freiberg.de

This is an Open Access article distributed under the terms of the Creative Commons Attribution-Noncommercial License (http://creativecommons.org/licenses/by-nc/3.0/), which permits unrestricted use, distribution, and reproduction in any noncommercial medium, provided the original work is properly cited. 


\section{Material and experimental procedure}

\subsection{Cast CrMnNi-TRIP-steel}

The high alloyed TRIP-steel was cast in discs showing a chemical composition as given in Tab. 1. Samples for tensile and compressive tests have been cut out of the discs, followed by a subsequent annealing at $1050^{\circ} \mathrm{C}$ for $0.5 \mathrm{~h}$ in vacuum and quenching in water.

Table 1. Chemical composition of the high alloyed cast CrMnNi-TRIP-steel.

\begin{tabular}{llllllll}
\hline & $\mathrm{Fe}$ & $\mathrm{C}$ & $\mathrm{Cr}$ & $\mathrm{Mn}$ & $\mathrm{Ni}$ & $\mathrm{Si}$ & $\mathrm{Al}$ \\
\hline $\mathrm{wt} \%$ & bal. & 0.03 & 15.5 & 6.1 & 6.1 & 0.9 & 0.1 \\
\hline
\end{tabular}

The resulting microstructure is coarse grained (grain size $0.1-1 \mathrm{~mm}$ ), characterized through dendritic solidification. A small volume fraction $(<3 \%)$ of $\delta$-ferrite is sustained from the casting process. The $\delta$-ferrite is mainly situated in the interdendritic spaces and as well at grain boundaries of the austenite. Based on the chemical composition the SFE can be estimated through empirical equations [6-8]:

$$
\begin{gathered}
\gamma_{\mathrm{SF}}=-53+6.2 \% \mathrm{Ni}+0.7 \% \mathrm{Cr}+3.2 \mathrm{Mn}+9.3 \% \mathrm{Mo}=15.0 \mathrm{~mJ} / \mathrm{m}^{2} \\
\gamma_{\mathrm{SF}}=16.7+2.1 \% \mathrm{Ni}-0.9 \% \mathrm{Cr}+26 \% \mathrm{C}=16.4 \mathrm{~mJ} / \mathrm{m}^{2} \\
\gamma_{\mathrm{SF}}=25.7+2 \% \mathrm{Ni}+0.9 \% \mathrm{Cr}+1.2 \% \mathrm{Mn}+410 \% \mathrm{C}+77 \% \mathrm{~N}-13 \% \mathrm{Si}=15.8 \mathrm{~mJ} / \mathrm{m} 2
\end{gathered}
$$

\subsection{Mechanical testing}

Mechanical tests were performed at a Zwick 1476 testing system with a climate chamber for tensile tests with a strain rate of $4 \cdot 10^{-4} \mathrm{~s}^{-1}$. For the compressive mode a servo-hydraulic MTS 810 test machine was used with a strain rate of $1 \cdot 10^{-2} \mathrm{~s}^{-1}$. Due to testing reasons a different strain rate for tensile and compressive tests had to be applied. But former experiments showed that there is nearly no difference in the stress strain response under compression to the lower rate of $4 \cdot 10^{-4} \mathrm{~s}^{-1}$, which was used for the tensile tests. For examinations on the microstructure the samples were cut longitudinal, so that information always is obtained from centre part of the specimens, which is especially necessary for the compression tests.

\subsection{EBSD measurements}

For determination of the phase distribution and grain orientations EBSD measurements were applied. Samples were cut in half to generate RD-TD planes. Samples have been ground, followed by an electropolishing. For the EBSD measurements a FEGSEM LEO 1530 GEMINI at 15 or $20 \mathrm{kV}$ acceleration voltage and the HKL Channel5 software was utilised.

\subsection{Phase fraction determination}

To quantify the phase fractions several methods were used. First of all a magnetic balance was applied. Small sample parts were dissected. Only the ferromagnetic fraction (bcc) can be measured. The amount of initial $\delta$ ferrite has to be considered. As additional method quantitative light optical microscopy has been carried out. The samples have been ground and polished and were subsequently etched with Beraha II solution. Via detection of grey scale pictures the areas have been determined according to the phases.

\section{Results and Discussion}

\subsection{Mechanical characterisation}

In Fig. 1 the flow curves for tensile and compressive loading as function of temperature are presented. It becomes evident that at low temperatures the highest strength was observed on the expense of strain. The sigmoidal shape above $60^{\circ} \mathrm{C}$ proves the existence of $\alpha^{\prime}$-martensite, which is mainly responsible for increased workhardening [5]. It is quite obvious that the material behaviour under plastic deformation changes between 20 and $60^{\circ} \mathrm{C}$. This proves that there must be a characteristic change in deformation mode. Above $60^{\circ} \mathrm{C}$ the curves tend to show no pronounced work hardening, compared to lower temperatures. It is evident, that the maximum 
energy absorption is achieved around room temperature (RT). The measure of the specific energy absorption is given by the integration of the area below the flow curve. It is supposed, that the increased yield strength for low temperature compression tests is due to the isothermal formation of $\alpha^{\prime}$-martensite. The lowered temperature led to a fast transformation of the austenite into $\alpha^{\prime}$-martensite just before the test or within the elastic part of the deformation. Thus the flow stress is increased, because $\alpha^{\prime}$-martensite is already formed.
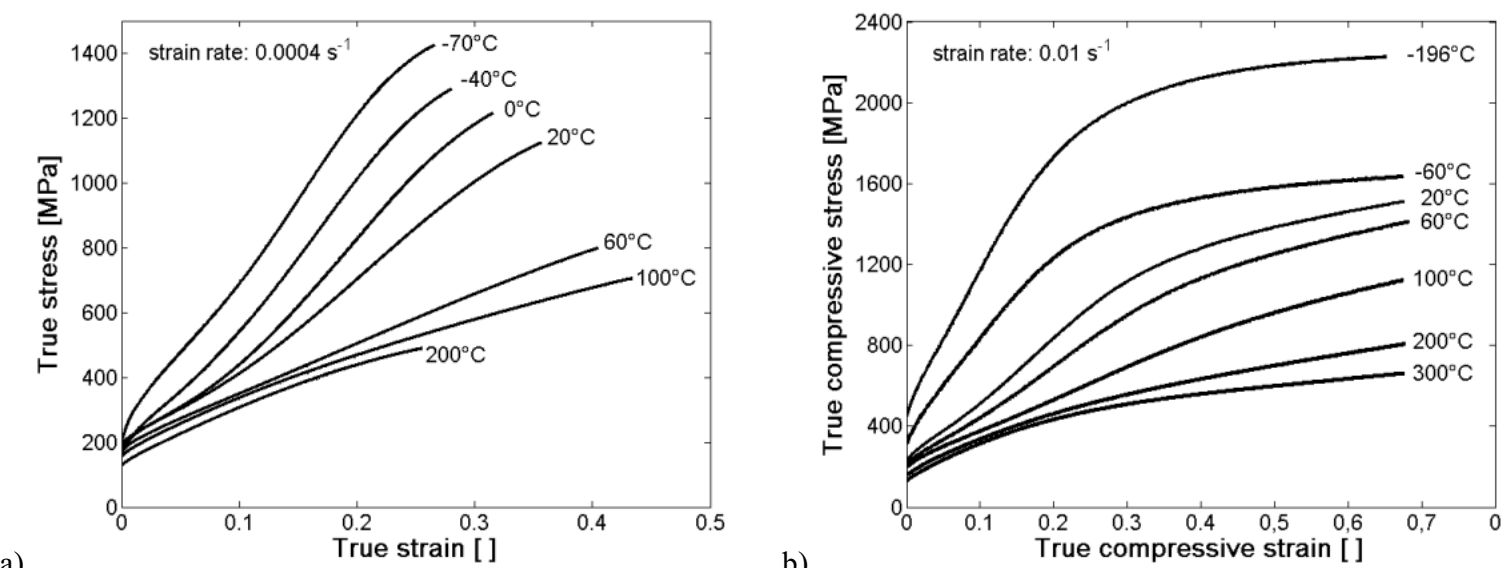

Fig. 1. Flow curves as function of temperature from a) tensile $\left(\dot{\varepsilon}=4 \cdot 10^{-4} \mathrm{~s}^{-1}\right)$ and b) compressive tests $\left(\dot{\varepsilon}=10^{-2} \mathrm{~s}^{-1}\right)$.

The extracted parameters of the stress strain curves are shown in Fig. 2. The cast material shows the typical anomalous temperature behaviour of the flow stress and the total elongation as known from literature [2, 9]. The maximum of the strain anomaly is situated between 60 and $100^{\circ} \mathrm{C}$. Three possible phase transformations may occur within this temperature range: $\gamma \rightarrow \alpha^{\prime}, \gamma \rightarrow \varepsilon$ or $\varepsilon \rightarrow \alpha^{\prime}[2]$. Above $60^{\circ} \mathrm{C}$ the upper part of the anomalous behaviour seems to be attributed to superposition of the TRIP and the TWIP (TWinning Induced Plasticity) effect, as the SFE rises and the critical initiation stress for twins is reached. First results on this transition have been obtained, but further work has to be conducted to confirm this. In this study the microstructure of the tests at RT and the phase composition will be explored. For this purpose interrupted deformation tests have been performed at $5,10,15,25,35$ and $45 \%$ nominal deformation.

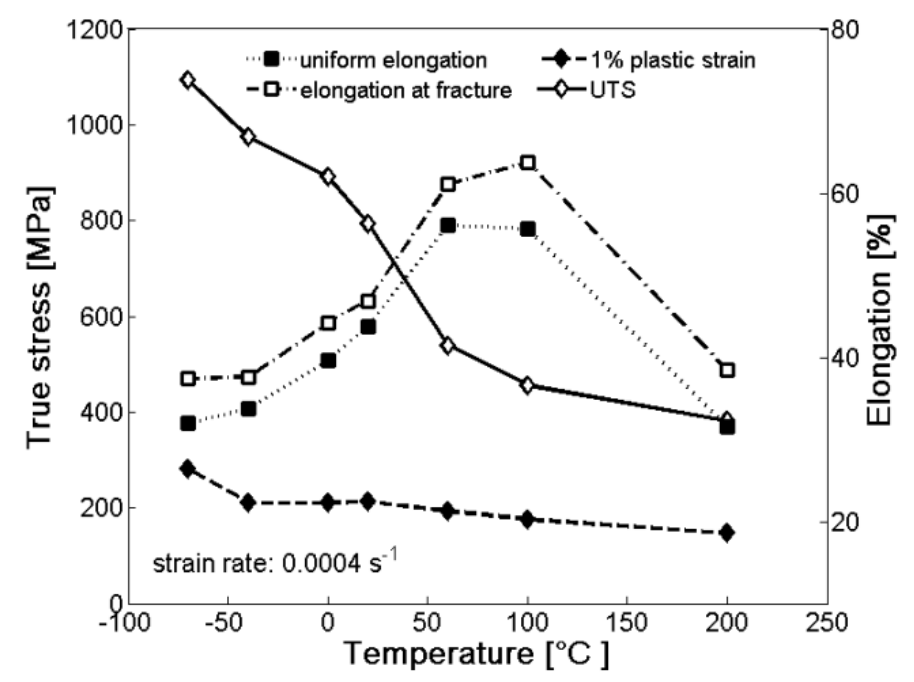

Fig. 2. Anomalous behaviour of the ultimate tensile strength, flow stress and elongation as a function of temperature of the cast CrMnNi-TRIP-steel determined from tensile tests.

\subsection{Microstructure characterisation}

To gain information about the microstructure, specimens have been examined in terms of light optical microscopy, EBSD and magnetic balance. In Fig. 3 the initial microstructure state is illustrated through a light optical micrograph (Fig. 3a) and an EBSD measurement showing the austenitic grains as image quality map, as well as the fine distributed $\delta$-ferrite (blue) (Fig. 3b). The grey shades of the measured austenite grains are related to the density of defects or internal stresses. Dark lines are caused for example by low angle grain boundaries (LAGBs) or high angle grain boundaries (HAGBs) and clustered defects. At these areas the lattice is disturbed and the quality of the resulting Kikuchi lines decreases. Hence these lines are a good indicator for defects or interfaces. 

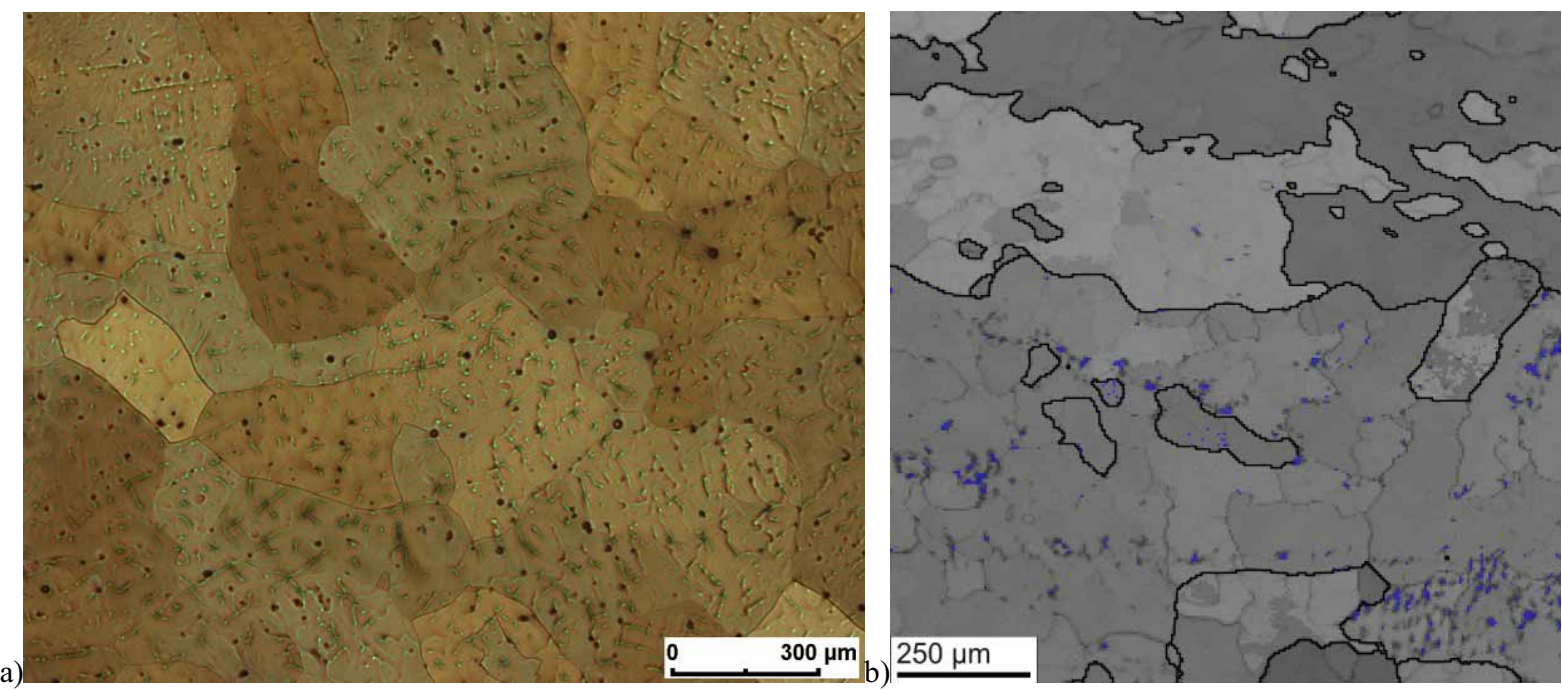

Fig. 3. Microstructure of the initial state: a) LOM-micrograph indicates segregations at the interdendritic spaces through different etching behaviour, b) EBSD image quality map depicting HAGBs within the austenite (thick black lines) and $\delta$ ferrite (blue).

In Fig. 4 the microstructure after 5\% compressive deformation is shown. Pronounced deformation bands are visible as a typical phenomenon. In Fig. 4a different grains are showing distinct directions of deformation bands, which is due to the grain orientation and the Schmid factor for the activation of slip systems. According to the Schmid factor different grains show distinct deformation band densities, as well as different angles between load direction and deformation band. The deformation bands exhibit an angle of $45^{\circ}$ within the grains that deform first. At 5\% nominal compressive deformation $\alpha^{\prime}$-martensite is formed at the intersections of deformation bands but mostly in the volume of the bands (Fig. 4b: black arrows), which was identified by EBSD measurements as will be shown later. The microstructure tends to be similar for compressive and tensile load at small deformation ranges.
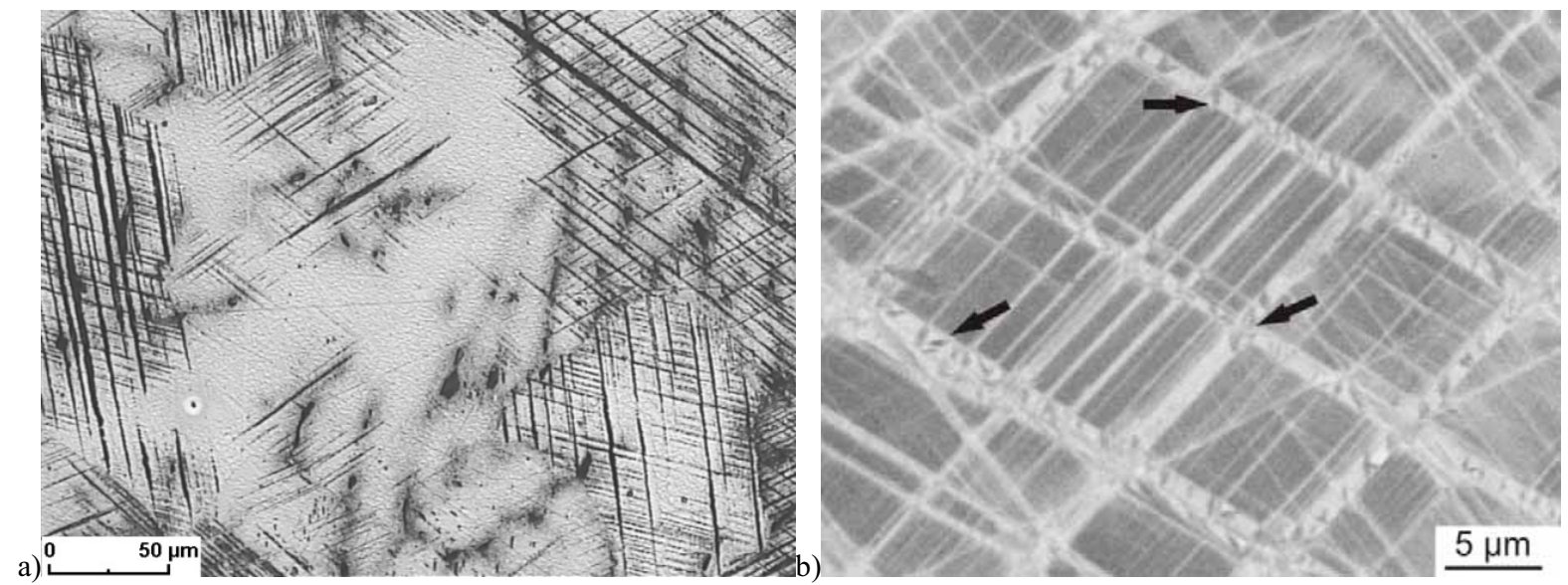

Fig. 4. Cast TRIP-steel sample after 5\% nominal compressive deformation: a) LOM micrograph showing the arrangement of the deformation bands within different grains, b) SEM micrograph (backscattered electrons contrast), black arrows indicate the formation of $\alpha^{\prime}$-martensite within deformation bands.

The nature of the deformation bands is shown in Fig. 5. Only a part of one big austenitic grain was measured. Darker lines within the austenite are referred to a higher density of defects in the deformation bands. Some of the deformation bands, namely the wider parts could not be allocated to fcc or bec structure, as they are exhibiting an hep lattice (Fig. 5a), represented by an indexed hexagonal Kikuchi pattern in Fig. 5b. It should be noted that only the wider parts are indexed hexagonal. This can be explained by the density of stacking faults which increases with wider deformation bands. As mentioned before, diverged edge dislocations may form a hexagonal stacking sequence when they appear on every second $\{111\}$ plane of the austenite. Therefore it seems that if a sufficient stacking fault density is reached, the deformation bands tend to show a hexagonal lattice called $\varepsilon$-martensite. This becomes more likely when the low SFE is considered. 

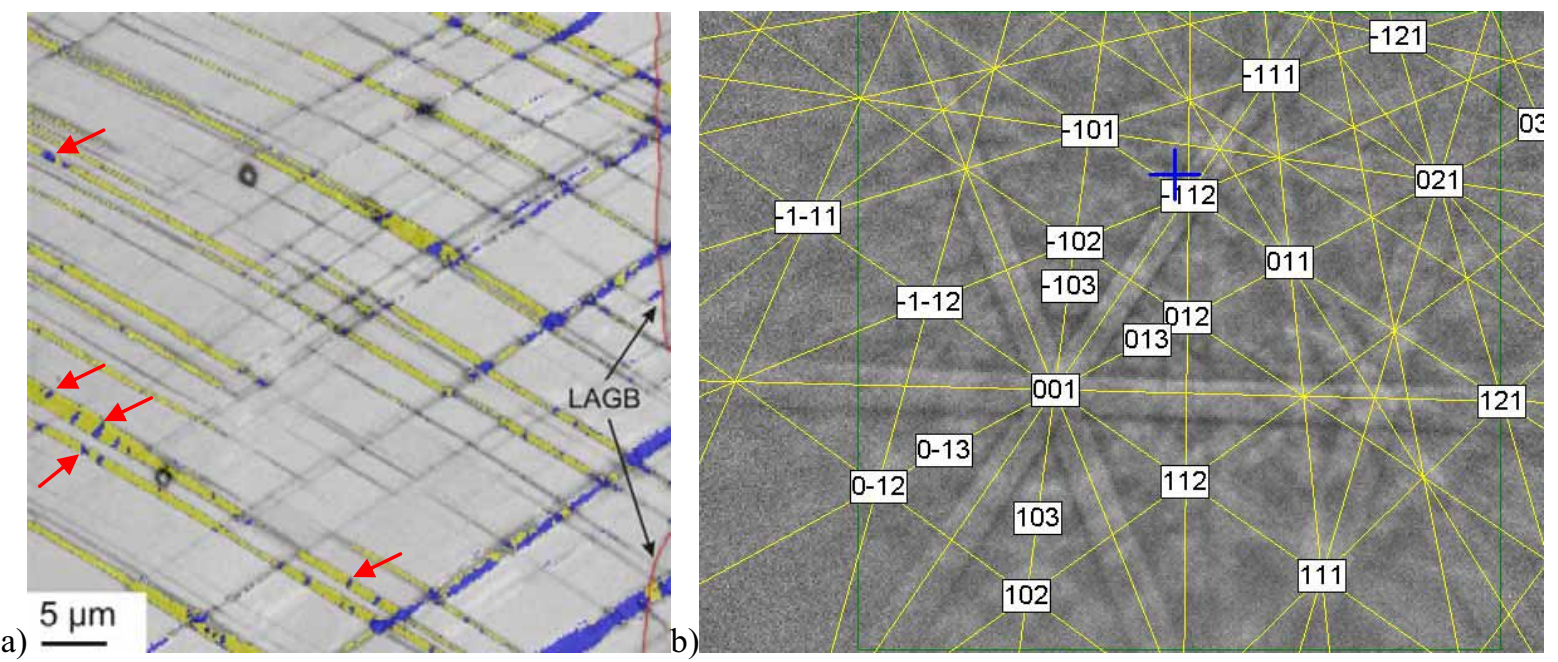

Fig. 5. EBSD measurement after 5\% compressive deformation, a) image quality map showing the phase transformation within the deformation bands (fcc - grey scale, hcp - yellow, bcc - blue), b) indexed Kickuchi-pattern of hcp deformation bands.

At the right side of Fig. 5a the deformation process is shown exemplary, as nearly the complete width of the $\varepsilon$-martensite is transformed to bcc ( $\alpha^{\prime}$-martensite). It is a well know phenomenon that $\alpha^{\prime}$-martensite nucleates at the intersections of $\varepsilon$-plates [2, 10-12]. But as shown in Fig. 5a, $\alpha^{\prime}$-martensite nucleates not only at intersecting deformation bands. $\alpha^{\prime}$-martensite embryos can be found in the volume of the plate as well (Fig. 5a: red arrows). The $\varepsilon$-martensite is highly metastable and transforms to $\alpha$-martensite by the coalescence of several small bcc areas which nucleated within the deformation bands [13]. On the right side of Fig. 5a a LAGB is located. Therefore dislocation movement is impeded and the resulting stress promotes the $\varepsilon \rightarrow \alpha^{\prime}$ transformation. Based on the instability of the hep phase and the highly bcc stabilizing effect of chromium, only small amounts $(<10$ vol.\%) of hcp phase can be found within the investigated samples.

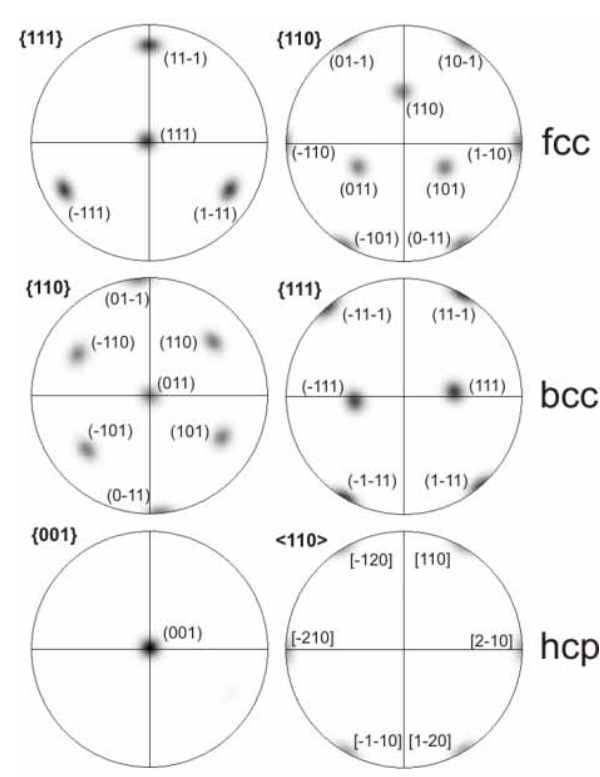

Fig. 6. Pole figures showing orientation relationship of the fcc, bcc and hcp phase after $5 \%$ nominal compressive deformation obtained from EBSD.

Under compressive load the predominant orientation relationship between austenite and $\alpha^{\prime}$-martensite is found to be Kurdjumow-Sachs relation (K-S), shown in Fig. 6. The observed parallelism of $(111)_{\gamma} \|(011)_{\alpha^{\prime}}$ lattice planes and [10-1 $]_{\gamma} \|[11-1]_{\alpha^{\prime}}$ directions is in good agreement with the literature[14]. The $\varepsilon$-martensite shows an orientation relation of $(111)_{\gamma}\left\|(001)_{\varepsilon}\right\|(011)_{\alpha^{\prime}}$ and $[10-1]_{\gamma}\left\|[110]_{\varepsilon}\right\|[11-1]_{\alpha^{\prime}}$ as described in [10]. Totally $3 \mathrm{~K}-\mathrm{S}$ variants of $\alpha^{\prime}$-martensite can be counted from 24 theoretical possibilities within the data set of Fig. 5. These variants delineate each other mainly with $<111>60^{\circ},<111>57.2^{\circ}$ or $<110>60^{\circ}$ axis/angle rotations [15]. Under tensile loading the orientation relationship is slightly shifted around approximately $2-3^{\circ}$, which fits the Greninger-Troiano relationship $[2,16]$. The number of formed crystallographic variants is due to the selective effect of the applied external load $[17,18]$. The formed variants contribute to the high amount of overall strain $[5,12]$. At higher strains or equivalent stresses the increased contribution of the $\alpha^{\prime}$-martensite on workhardening of the $\alpha^{\prime}$-martensite is recognized when additional slip systems are activated and the $\alpha^{\prime}$-martensite is a hard obstacle for dislocation movement.

According to higher deformation states, the density of deformation bands is rising, as well as their width is increasing due to the applied stress (Fig. 7a). Neighbouring $\alpha^{\prime}$-martensite areas are growing [17] and nearly whole grains are transformed. Interfaces showing a $\Sigma 3$ relationship inside the $\alpha^{\prime}-$ martensite originate from the coalescence of the martensite nuclei (Fig. 7b). Initial austenite grain boundaries act as obstacle for the deformation bands and the subsequently formed martensite. Therefore the term 'deformation band' was chosen and not 'shear band' as these would persist over the HAGBs. HAGBs are the preferred nucleation site for the bands. The deformation stress can be transferred onto neighbouring grains, initiating deformation bands as well. Thus it seems that the $\alpha^{\prime}$-martensite starts to grow as larger domain at the boundaries of the initial austenite grains which exhibit suitable orientations in terms of the Schmid factor for dislocation glide. 

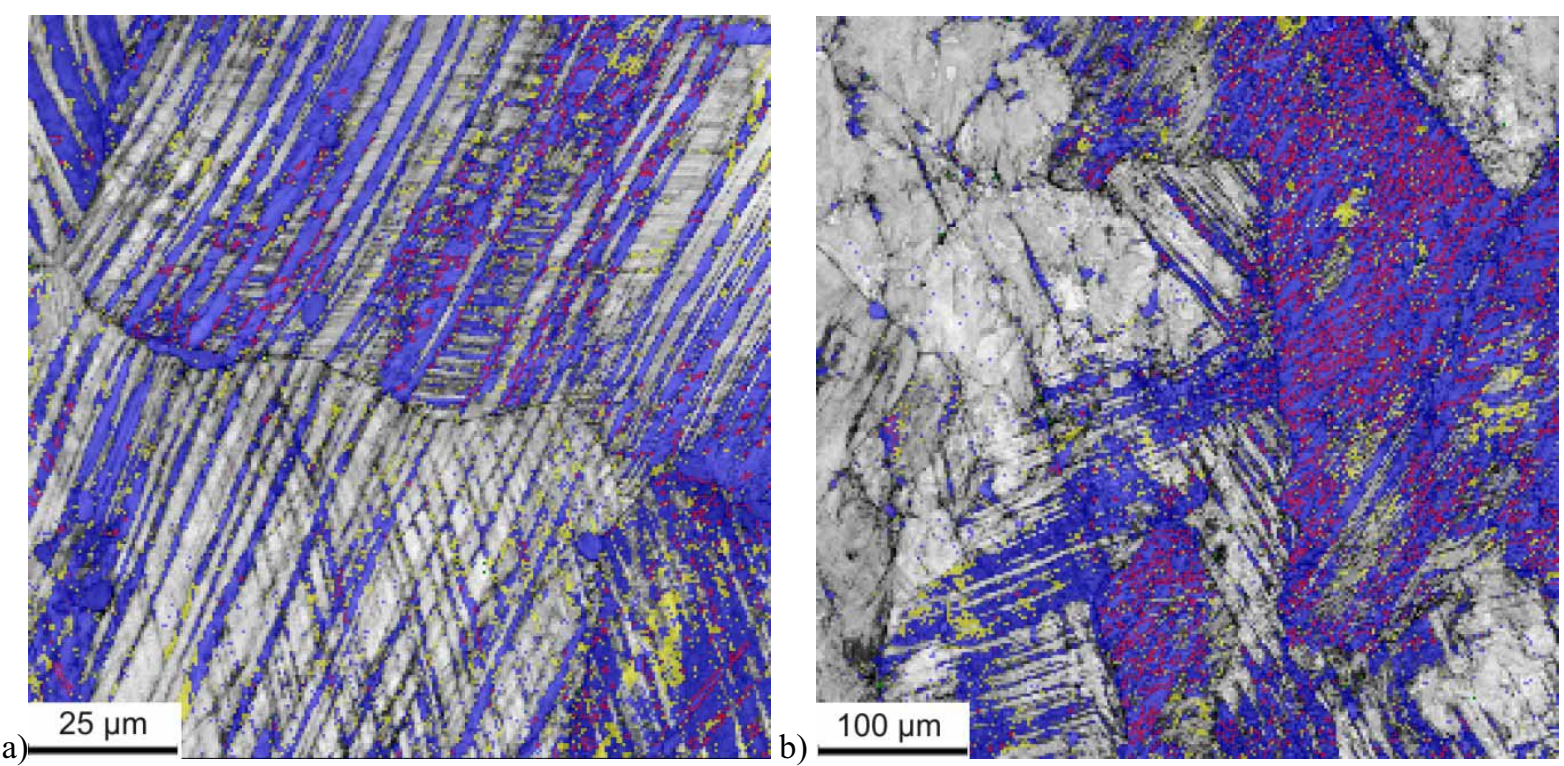

Fig. 7. EBSD measurements showing the microstructure of deformed tensile samples after $25 \%$ nominal deformation, a) image quality map: bands are getting wider (fcc - grey scale, hcp - yellow, bcc - blue, $\Sigma 3$ boundaries - red), b) image quality map: separate bands coalesce and form one big martensitic domain, separated through twin boundaries displayed in red (fcc - grey scale, hcp - yellow, bcc - blue).

The evolution of the bcc phase fraction versus strain is depicted in Fig. 8. It has to be mentioned, that an amount of approximately 3 vol.\% must be dedicated to $\delta$-ferrite of the initial microstructure. All measured bcc phase fractions seem to fit well with each other, except the values determined from LOM. One reason could be that a distinction between deformation bands and martensite by colour etching is not always obvious in terms of grey scale. Increasing values of bcc phase by EBSD measurements at high strains are caused by the immense work hardening of the fcc phase and the connected decreasing detection rate.
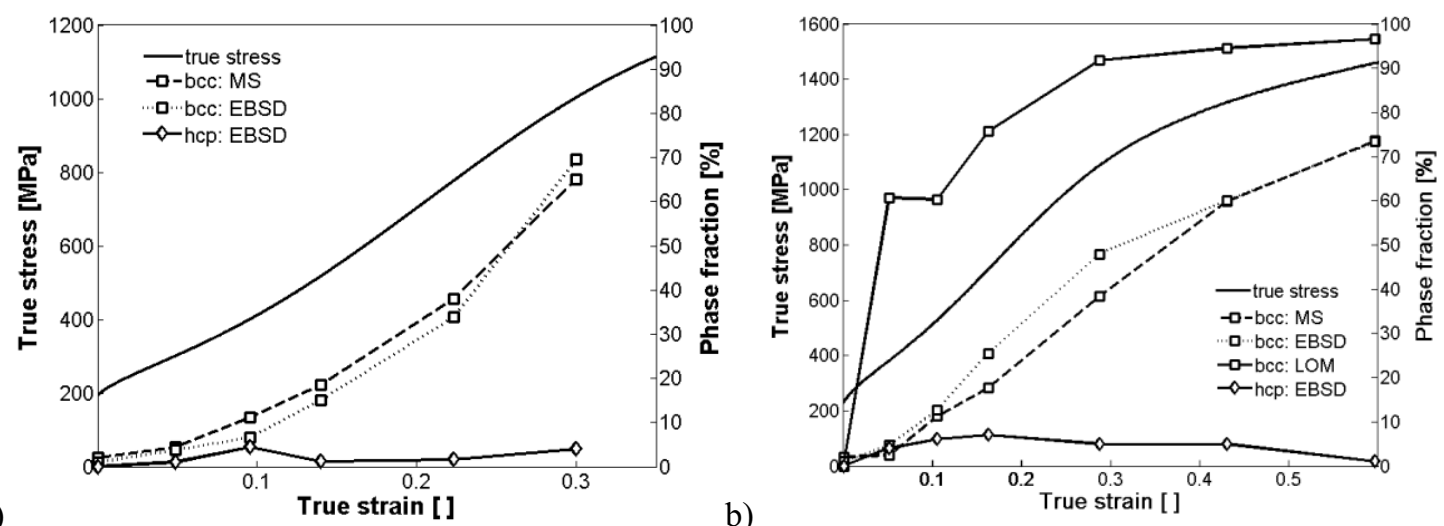

Fig. 8. Flow curves and bcc and hep phase fraction for a) tensile load and b) compressive load determined via EBSD, magnetic scale (MS) and light optical microscopy (LOM).

The amount of hep phase is always below $10 \%$ and indicates a maximum at the strain values of $0.10-$ 0.15 . If the shape of the flow curves is compared to the shape of the $\alpha$-martensite curve, they exhibit similar behaviour. Compared on the basis of equivalent strain, more $\alpha^{\prime}$-martensite evolves under tensile load. This experimental finding agrees well with the circumstance that there is a positive volume change of approximately 2.7 vol.\% during transformation. Hereby the transformation towards $\alpha^{\prime}$ is hindered under compressive conditions. As there is a small volume contraction of 0.8 vol.\% [20] during the $\gamma \rightarrow \varepsilon$ transformation the slightly higher amount of hcp phase can be explained for compression tested samples.

\section{Conclusions}

Mechanical and microstructural investigations on high alloyed CrMnNi-TRIP-Steel, deformed by interrupted uniaxial tests, have been presented. It was shown that within the characteristic deformation bands an hep phase evolves. The deformation bands act as dominating nucleation sites for $\alpha$-martensite formation. Two transformation places are observed: $\alpha^{\prime}$-martensite forms at intersections of deformation bands as well as within the deformation bands. A direct formation $\gamma \rightarrow \alpha^{\prime}$-martensite was never observed outside deformation bands but cannot be 
excluded. The $\varepsilon$-martensite is transforming rapidly to bcc structure, by coalescence of several individual small $\alpha^{\prime}$-martensite regions. This is stated by the fact that within the same grain and in the same slip system $\varepsilon$-martensite just formed and already $\alpha^{\prime}$-martensite nuclei can be found. As well as the bcc-stabilising effect of chromium and the small amounts of hcp phase which were measured by EBSD are indications for this assumption. The hexagonal $\varepsilon$-martensite seems to be a metastable transition phase, so that a deformation mechanism of $\gamma(\mathrm{fcc}) \rightarrow \varepsilon(\mathrm{hcp}) \rightarrow \alpha^{\prime}$ (bcc) can be assumed at room temperature. By reason of the formation of small $\alpha^{\prime}-$ martensite regions within the large fcc grains, a grain refinement occurs in the most stressed sites of the microstructure. At room temperature the formation of $\alpha^{\prime}$-martensite is the dominant deformation mechanism which is shown through the sigmoidal shape of the flow- and phase fraction curves. Whether deformation bands may be detected as hcp structure or as localised occurrence of stacking faults is probably connected to a critical density of stacking faults. Furthermore it is necessary to accomplish TEM investigations to reveal the intrinsic arrangement of defects due to deformation.

\section{References}

[1] A. Weiß, H. Gutte, M. Radke, P. Scheller, patent specification WO002008009722A1.

[2] F. Lecroisey, A. Pineau, Metallurgical Transactions A 3, 387 (1972)

[3] J. Talonen, H. Hänninen, Acta Materialia 55, 6108 (2007)

[4] K. Sato, M. Ichinose, Y. Hirotsu, Y. Yasunobu, The Iron and Steel Institute of Japan International 29, 868 (1989)

[5] B. Petit, N. Gey, M. Cherakaoui, B. Bolle, M. Humbert, Experimental and micromechanical modelling, International Journal of Plasticity 23, 323 (2007)

[6] R. Schramm, R. Reed, Metallurgical Transactions A 6 1345(1975)

[7] P. Brofman, G. Ansell, Materials Transactions A 9 , 879 (1978)

[8] F. Pickering, Physical metallurgical development of stainless steels, Proc. Conf. Stainless Steels Göteborg (1984), The Institute of Metals, London (1985) p. 2.

[9] G. Huang, D. Matlock, G. Krauss, Metallurgical transactions A 201239 (1989)

[10] H. Schumann, Kristall und Technik 11, 663 (1976)

[11] G. Olson, M. Cohen, Metallurgical Transactions A 6 ,795 (1975)

[12]P. Kelly, The Acta Metallurgica 13 ,635 (1965)

[13]L. Murr, K. Staudhammer, S. Hecker, Metallurgical Transactions A 13 627(1982)

[14] G. Kurdjumow, G. Sachs, Über den Mechanismus der Stahlhärtung/[On the mechanism of steel hardening], Mitteilung aus dem Kaiser Wilhelm-Institut für Metallforschung (1935) p. 325.

[15] S. Morito, X. Huang, T. Furuhara, T. Maki, N. Hansen, Acta Materialia 545323 (2006)

[16] A. Greninger, A. Troiano, Transactions of the american institute of mining and metallurgical engineers 185589 (1949)

[17] W. Liu, H. Bunge, Variant, Materials Letters 10336 (1991)

[18] Y. Higo, Acta Metallurgica 22313 (1974)

[19] K. Easterling, A. Thölen, Acta Metallurgica 28, 1229 (1980)

[20]H. Schumann, Dilatationseffekte bei martensitischen Umwandlungen/ [Dilatation effects at martensitic Transformations], Wissenschaftliche Berichte des Zentralinstitut für Festkörperphysik und Werkstofforschung 20 (1979) p. 137. 